Programa de Pós-Graduação em Engenharia de Produção - PPGEP

Laboratório de Qualidade de Vida - LaQVida

Universidade Tecnológica Federal do Paraná - UTFPR

Ponta Grossa - PR - Brasil

v. 05 , n. 03 , jul./set. 2013 , p. $100-103$

DOI: $10.3895 / \mathrm{S} 2175-08582013000300011$

\section{REVISTA BRASILEIRA DE QUALIDADE DE VIDA}

\title{
Entrevista realizada com Roberto Vilarta
}

\author{
Guanis de Barros Vilela Junior \\ Universidade Metodista de Piracicaba - UNIMEP - Piracicaba - Brasil \\ Faculdades Metropolitanas de Campinas - METROCAMP - Campinas - Brasil \\ guanis@gmail.com
}

Roberto Vilarta é Professor Titular na Área de Qualidade de Vida, Saúde Coletiva e Atividade Física na Universidade Estadual de Campinas (UNICAMP), tem formação em Fisioterapia pela Universidade Federal de São Carlos (1983), Mestre em Ciências Biológicas pela Universidade Estadual de Campinas (1986), Doutor em Ciências pela Universidade de São Paulo (1990), LivreDocente em Educação Física pela Unicamp (1996). Atua há 28 anos na Faculdade de Educação Física da UNICAMP desenvolvendo ensino e pesquisa em temas sobre a promoção da saúde e a atividade física, qualidade de vida em idosos praticantes de atividade física, intervenções de responsabilidade social em empresas, avaliação da alimentação saudável e prática de atividade física. Docente laureado com 'Bolsa Reconhecimento Acadêmico Zeferino Vaz' (1995), com 'Prêmio Reconhecimento Acadêmico Zeferino Vaz' (2007) e com 'Prêmio Reconhecimento Docente na UNICAMP pela Dedicação ao Ensino de Graduação' (2012). Com vida acadêmica profícua já orientou mais de 30 alunos de mestrado e doutorado, o Professor Roberto Vilarta prima pela transparência e conduta ética na condução de suas atividades na Faculdade de Educação Fisica (FEF) - UNICAMP.

Ressalta-se que foi mantida a entrevista na íntegra, visando preservar a originalidade do depoimento gentilmente oferecido pelo entrevistado, o qual agradecemos enormemente de antemão.

\section{Professor Roberto Vilarta, poderia pontuar como e quando começou a se interessar pela área de investigação da qualidade de vida e atividade física?}

Junto com o Prof. Aguinaldo Gonçalves e o Prof. Gustavo Luis Gutierrez, docentes da FEF - UNICAMP, em 1997, percebemos movimentos dos profissionais de saúde buscando capacitações de pós-graduação em temáticas não tradicionais relativas aos desafios que enfrentavam no seu cotidiano. Temas abrangentes como as terapias alternativas, reeducação postural e alimentação saudável exigiam abordagens metodológicas diferenciadas, no entanto a visão de pesquisa instituída não se mostrava muito receptiva nem valorizava os projetos que se apresentavam para financiamento ou vinculação a programas de capacitação. Uma área emergente na época iniciava investigações sobre qualidade de vida, mostrando-se bem fundamentada pelas incursões da Organização Mundial de Saúde nessa frente, tendo por base o projeto WHOQOL. 
2. O senhor poderia discorrer sobre o processo de consolidação de seu grupo de estudos em atividade física e qualidade de vida, que como sabemos é uma referência nacional?

Refuto os qualificativos que privilegiam índices sustentados pelas citações de artigos, publicações ao ano e rankings acadêmicos. Eu tento compreender as pessoas que estão vinculadas ao grupo de estudos, não como co-autores, mas sua condição especial, seus anseios, sonhos e suas perspectivas de vida, suas formas de conviver e se realizar. Referências nacionais se constroem à custa de muito trabalho e determinação, mas são efêmeras. Prefiro valorizar os relacionamentos dentro do grupo de estudos, esses sim são mais duradouros e constroem vida com qualidade.

3. Nunca se pesquisou (e se gastou) tanto sobre qualidade de vida no Brasil e no mundo, não obstante, as pesquisas mostram que a percepção da qualidade de vida tem piorado, quero dizer, existe um aumento claro de epidemias relacionadas às doenças crônico-degenerativas tais como obesidade, hipertensão, diabetes, dentre outras. O que está errado nesta equação?

De um lado dessa equação temos a falta de um projeto nacional de desenvolvimento sustentado pela educação. Essa 'lição de casa' ainda está por ser materializada no nosso país. Adicionam-se condições de vida impróprias - habitação, trabalho, paz - que nos dificultam o exercício pleno dos nossos potenciais físicos, emocionais e intelectuais. Do outro lado da equação sobra a noção de não pertencimento social ou comunitário, o desprezo pelo que é 'público' e a sensação de impunidade. Mas onde ficam as doenças crônicas não transmissíveis? Todos nós sabemos que elas são ligadas à nossa herança genética, sexo e idade, no entanto há muitos fatores que podemos modificar positivamente. Citam-se os relacionados ao estilo de vida, esta inclusive, uma área de atuação profissional dos educadores, em especial os de educação física. Modificar hábitos e comportamentos não é tarefa fácil, mas os educadores voltam ao foco como elementos essenciais para a estruturação de uma sociedade onde a qualidade de vida seja mais valorizada do que o consumo e exposição pública de nosso cotidiano.

4. Pesquisar sobre Qualidade de Vida é um modismo acadêmico com várias heresias metodológicas sendo cometidas ou trata-se de uma área de investigação consolidada?

Certamente haverá avanço do conhecimento até os limites que nos permitam ampliar nossa compreensão sobre o que realmente importa para atingirmos qualidade de vida plena. Interessante notar inúmeros relatos de pessoas nessa condição de 'vida plena', mesmo quando as percebemos 'com poucas condições'... Heresias metodológicas são comuns em linhas de pesquisa tão desafiantes quanto inovadoras, como é o caso da qualidade de vida. O que me deixa um pouco abismado é o fato de termos conhecimentos técnicos sobre alimentação, atividade física, engenharia e humanidades que proveriam vida digna e saudável para quase $100 \%$ da população, no entanto não se consegue chegar ao público alvo com todo esse progresso. De novo voltaríamos com o tema das condições de vida impróprias - habitação, trabalho, paz - discutido acima. 
5. Um possível entendimento da qualidade de vida, a compreende como o resultado da mediação que fazemos entre aquilo que temos e aquilo que somos. Nesta balança, entre o ter e o ser, qual pesa mais para a qualidade de vida das pessoas?

Gosto muito de olhar nossa vida pelo viés da história evolutiva. Temos, não há como negar, um passado evolutivo vitorioso, afinal estamos vivos, o que já é um fato incomum frente às milhões de espécies extintas neste breve átimo de vida no planeta. Nosso genoma humano é o que temos de mais palpável, pois acumula informações importantes da história desse sucesso. De outro lado, somos o resultado da interação do genoma com o ambiente (aulas de biologia do ensino fundamental, lembram?), mas o complicado, dessa outra equação, está centrado no fato de estarmos num ambiente provavelmente mais agressivo que já experimentamos até hoje (peço que desconsiderem os leões!). Agressivo ao ponto de nos oferecer oportunidades de permanecermos sedentários a vida toda, adotarmos posturas contorcidas nos sofás da moda e ingerirmos comida industrializada. Voltando para a história evolutiva, podemos até nos perguntar: Será que este foi um final imaginado por aqueles sujeitos bípedes que habitaram as savanas africanas há 4,5 milhões de anos?

6. Em tempos de manifestações públicas Brasil afora, onde a população apresenta um rosário de reivindicações, como o senhor vê as políticas públicas para a promoção da saúde e da qualidade de vida em nosso país?

Provavelmente vou me repetir sobre o que já respondi acima: Educação como base. Condições de vida como essência da estabilidade social. Atitudes pessoais responsáveis para consigo mesmo, em especial.

7. Como o senhor vê a questão do progresso econômico e a qualidade de vida no trabalho?

Progresso econômico fundamentado nos mercados de risco e as empresas sendo obrigadas a pagar $90 \%$ dos lucros em dividendos aos acionistas, não me parece um ambiente no qual os administradores estejam interessados na qualidade de vida de seus colaboradores. Sempre gosto de pensar no 'mundo ideal do local de trabalho' onde as ações de ginástica laboral são acompanhadas pelas de orientação da alimentação saudável, práticas de atividade física orientada e os grupos de apoio para tabagistas, diabéticos, hipertensos e práticas de auxílio ao controle do estresse.

8. O Grupo de Estudos em Qualidade de Vida e Atividade Física disponibiliza na internet, gratuitamente, vários livros sobre a temática da qualidade de vida e seus temas transversais; configurando um belo exemplo de socialização do conhecimento construído pelo grupo. O senhor tem informações relativas ao número de acessos e downloads dos mesmos?

O link para acesso está na página de entrada da FEF- UNICAMP. São cerca de 50 acessos semanais originados do Brasil e pequena parte do exterior. Vejo que os 25 livros disponibilizados são citados como referências de monografia e dissertações nos mais distantes locais do país, o que me dá uma satisfação imensa. 


\section{9. É notório seu rigor no trato do planejar, quais são os planos para o futuro próximo?}

Acho bastante interessante compreender como se dá a relação entre os domínios da qualidade de vida nos ambientes laborais e da escola, pois acredito que esses podem evoluir positivamente nos próximos anos, capacitando os jovens e os adultos para a adoção de hábitos e comportamentos mais adequados à vida plena, obviamente sempre acompanhados de condições de vida excelentes providas pelo poder público. 